\title{
O “ATEÍSMO NEW AGE”? MORALIDADE E ESPIRITUALIDADE EM SAM
}

\section{HARRIS}

\author{
The "New Age Atheism"? An Atheistic Morality and Spirituality at Sam Harris
}

Danilo Monteiro Firmino ${ }^{1}$

\section{RESUMO}

O presente artigo procura discutir certos aspectos da tese de doutorado em andamento intitulada "Uma "Nova Era" no ateísmo: ciência moderna, espiritualidade e desencantamento religioso na perspectiva de Sam Harris”. O recorte estabelecido neste artigo procura investigar as relações entre o pensamento do filósofo e neurocientista ateu Sam Harris e as práticas conhecidas como Nova Era (New Age). Em sua busca pela moralidade e espiritualidade longe da influência religiosa e baseada na ciência, o autor pauta suas discussões em elementos e discussões recorrentes de círculos New Age, promovendo assim uma possível influência, mesmo não intencional, das ideias da Nova Era em suas reflexões.

Palavras-chave: Ateísmo, Nova Era, Sam Harris, Moralidade, Espiritualidade.

\begin{abstract}
This paper intents to discuss some aspects of the doctoral thesis in advance entitled "Uma "Nova Era" no ateísmo: ciência moderna, espiritualidade e desencantamento religioso na perspectiva de Sam Harris" (A "New Age" in the atheism: modern science, spirituality and religious disenchantment in the Sam Harris' perspective). The contour settled in this article plans to research the relations between the views of the philosopher and neuroscientist Sam Harris and the practices known as the New Age. Searching for morality and spirituality apart from religious influence and science-based, the author base his discussions in elements and discussions recurring at New Age's circles, promoting a so-called influence, intentionally or not, from the New Age's ideas in his works.
\end{abstract}

Keywords: Atheism, New Age, Sam Harris, Morality, Spirituality.

\section{INTRODUÇÃO}

O objetivo principal desse artigo é destacar Sam Harris, neurocientista e filósofo ateu, em sua proposta de desenvolvimento da moralidade e espiritualidade sem recorrer ao aspecto religioso e sem a interferência de eventos ditos sobrenaturais. Interessa principalmente as reflexões do autor expostas nas obras O Fim da Fé: a religião, terrorismo e o futuro da razão (2007), A Paisagem Moral: como a ciência pode determinar os valores humanos (2013) e

\footnotetext{
${ }^{1}$ Historiador. Doutorando em História Social na Universidade do Estado do Rio de Janeiro (UERJ-FFP). E-mail: dmf.1184@gmail.com
}

REVISTARELEGENSTHRÉSKEIA - 2020 - UFPR 
Despertar: um guia para a espiritualidade sem religião (2015). ${ }^{2}$ Para entender as questões morais e espirituais em Sam Harris, é de grande importância compreender parte de sua militância ateísta, pois os campos são relacionados e refletem sua atuação como integrante do amplo movimento ateu contemporâneo que se convencionou chamar "neo-ateísmo".

Sam Harris é uma figura polêmica em seu país natal, os EUA. O autor tem uma vasta produção, com seu conteúdo dedicado especialmente à defesa do ateísmo, moralidade e ética, divulgação científica, neurociência e aos estudos sobre a espiritualidade e meditação, observando em todos eles um constante viés antirreligioso. Grande parte de sua obra está disponível no site www.samharris.org, com destaque para a série de podcasts chamada Making Sense Podcast, ${ }^{3}$ onde Harris debate com cientistas, jornalistas e personalidades do meio acadêmico. Atualmente, segundo o site oficial do autor, Harris teve seus livros publicados em mais de 20 idiomas, participando de discussões em famosos meios como o The New York Times, Time, Scientific American, Nature, Rolling Stone, The Los Angeles Times, The Economist, The Times, The Boston Globe, The Atlantic, The Annals of Neurology, entre vários outros.

Em O Fim da Fé, escrito ainda no calor dos atentados de 11 de setembro de 2001 promovidos pela Al-Qaeda, Harris entende que é imperativo uma ação rápida e enérgica contra as religiões, pois todas são irracionais. O neurocientista procura demonstrar os constantes choques entre a racionalidade e religião no mundo moderno, analisando como a humanidade suspendeu a razão em nome da crença religiosa ao longo da história. A fé deve ser combatida, extinta, pois a mesma e sua capacidade de anular a razão vão levar a humanidade ao seu fim.

O autor fala pouco sobre sua vida pessoal, argumentando ser uma maneira de se preservar de seus detratores. Segundo a matéria Making Belief de Brad Greenberg, ${ }^{4}$ publicada em 2008 pela UCLA Magazine, ${ }^{5}$ O Fim da Fé foi responsável pelo autor ser considerado por muitos o líder do “despertar” ateu nos EUA. ${ }^{6}$ Na ocasião do lançamento dessa obra, o autor era

\footnotetext{
${ }^{2}$ A cópia de O Fim da Fé analisada no artigo foi publicada pela editora portuguesa Tinta da China. As versões examinadas de Carta a uma nação cristã, A Paisagem Moral e Despertar foram publicadas em português pela editora Companhia das Letras. Os nomes originais e datas das obras quando publicadas nos EUA são: The End of Faith (2004), Letter to a Christian Nation (2006), The Moral Landscape: How can science determine moral values (2010) e Waking Up: searching for spirituality without religion (2014).

${ }^{3} \mathrm{O}$ sucesso desse programa rendeu ao autor a seleção da Apple no “iTunes Best” e o prêmio de melhor podcast no Webby Award na categoria de Ciência e Educação. Informação disponível em: https://samharris.org/about/. Essa série também pode ser vista integralmente no canal do Youtube oficial de Harris, https://www.youtube.com/user/samharrisorg. Ambos acesso em acesso em 16 de setembro de 2020.

${ }^{4}$ Disponível em http://magazine.ucla.edu/depts/quicktakes/making-belief/, acesso em 16 de setembro de 2020.

${ }^{5}$ Disponível em: https://newsroom.ucla.edu/magazine, acesso em 16 de setembro de 2020.

${ }^{6}$ A obra foi um sucesso de vendas. Segundo uma matéria publicada em 2006 pelo Washington Post chamada Atheist Evangelist, O Fim da Fé havia vendido até 270.000 cópias até então e recebeu o prêmio PEN/Martha Albrand (2005) de melhor obra de não -ficção. Segundo a mesma publicação, Carta para uma nação cristã, um livreto com menos de cem páginas lançado em 2006 com resposta aos críticos de O Fim da Fé, permanecia em $11^{\circ}$ lugar na lista de mais vendidos do The New York Times.
} 
formado em Filosofia por Stanford e estudante no doutorado de Neurociência da University of California (UCLA), em Los Angeles. É interessante notar que o livro foi rejeitado, de acordo com jornalista David Segal do The Washington Post, por quinze editoras antes de ser publicado pela Norton Company ${ }^{7}$. Além da radicalidade de suas ideias afastar possíveis interessados em publicar a obra, o fato de ainda estar cursando o doutorado era um problema na aceitação do seu trabalho.

Durante o seu doutorado estudou as distinções fisiológicas entre crença e descrença. Nessa pesquisa, usando imagens de ressonância magnética, percebeu que uma região do cérebro dedicada à crença, incerteza e descrença agia de maneira diferente de acordo com as declarações do sujeito enquanto ainda estava dentro da máquina de ressonância. Diante disso, conclui:

Se você receber uma proposta em que realmente não acredita, são apenas meras palavras (...) No momento em que você lhes dá crédito, ocorre uma transformação completa de sua neurologia, psicologia e fisiologia. A crença é a dobradiça sobre a qual a porta para o comportamento e a emoção se abre. ${ }^{8}$

Harris concluiu seu doutorado em 2009 e lançou A Paisagem Moral já consolidado como um fenômeno editorial. Essa obra objetiva principalmente combater a ideia de que a religião deve ser o guia para moral humana. Para o autor, a ciência moderna deve assumir esse papel, pois pode maximizar, empiricamente, o bem-estar e a busca do ser humano pela felicidade.

Despertar, seu livro menos antirreligioso, procura fornecer aos leitores uma série de dicas e técnicas para alcançar o bem-estar. As reflexões do autor nesse livro de "autoajuda" agem em duas direções: primeiro, demonstrar como as “experiências espirituais” são apenas processos neuroquímicos do cérebro, sendo por isso explicáveis pela ciência moderna; segundo, procurar ser um guia da “espiritualidade ateísta”, demonstrando como é possível a mente humana agir no corpo de maneira direta sem a necessidade de nenhum traço dito sobrenatural.

Além de sua formação científica, Harris afirma praticar meditação há mais de 30 anos, tendo estudado em países como Índia e Nepal. Foi aluno da conceituada professora de meditação Sharon Salzberg, escritora norte-americana que publicou diversos livros sobre o tema e que figura constantemente nas listas dos mais vendidos do The New York Times. ${ }^{9}$

\footnotetext{
${ }^{7}$ Disponível em: https://www.washingtonpost.com/wpdyn/content/article/2006/10/25/AR2006102501998_pf.html, acesso em 16 de setembro de 20.

8 Tradução minha, disponível em: http://magazine.ucla.edu/depts/quicktakes/making-belief/, acesso em 16 de setembro de 2020.

${ }^{9}$ Embora muito respeitada nos EUA, Salzberg teve apenas um livro traduzido para o português, A Real Felicidade: o poder da meditação (2013), disponível somente em formato eBook Kindle.
} 
O artigo procura apontar como Sam Harris, ao defender sua proposição de moralidade e espiritualidade afastada da religião e do misticismo, caminha em paralelo ao movimento Nova Era, ao utilizar diversas reflexões teóricas e práticas características desses grupos em suas argumentações para atingir o bem-estar e desenvolvimento espiritual.

Nesse sentido, suas reflexões geram questões interessantes: (1) assim como a Nova Era consegue influenciar, reinterpretar e ressignificar as crenças religiosas contemporâneas com práticas místicas/sobrenaturais que visam o bem-estar do indivíduo, a proposta de Harris não pode ser considerada pertencente ao que chamamos de Nova Era? (2) As reflexões de Harris podem ser um sinal das ressignificações da Nova Era no ateísmo, com práticas consideradas místicas “desencantadas” com a intenção que sejam praticadas até mesmo por um ateu militante com a “consciência tranquila”? (3) Estaríamos presenciando, com Harris, o surgimento de um “Ateísmo New Age”?

O artigo procura seguir as reflexões metodológicas da “história das religiões” proposta por Mircea Eliade, visando assim analisar as estruturas das ideias de Harris, aproximando-as das ideias correntes na Nova Era, da mesma forma que Eliade procura "construir a sua morfologia, inventariando as similitudes presentes entre os mais diferentes sistemas religiosos conhecidos pela humanidade” (HERMANN, 1997, 484).

As reflexões de Ciro Cardoso e Ronaldo Vainfas (1997), no que diz respeito a análise de conteúdo, serão observadas. De acordo com os autores, sempre que o estudioso se debruçar sobre o texto, precisa compreender que "um documento é sempre portador de um discurso que, assim considerado, não pode ser visto como algo transparente” (CARDOSO e VAINFAS, 1997, p. 539). Logo, a análise levará em consideração o momento histórico vivido, em especial o acirramento de conflitos de cunho religioso ocorridos posteriores aos atentados as Torres Gêmeas e sua influência nas obras de Sam Harris.

A análise do espaço virtual será de grande importância, pois é um dos meios para a divulgação das ideias de Harris, além de uma grande fonte de informações para o historiador. Como afirmou Fabio Almeida, “a Internet configura-se como uma nova categoria de fontes documentais para pesquisas históricas” (ALMEIDA, 2011, p. 9), sendo um local privilegiado para a divulgação das experiências ateístas da contemporaneidade.

\section{CONTRACULTURA E TRANSFORMAÇÃO NA ERA DE AQUÁRIO}

A definição do que seria a Nova Era é bastante problemática, muito em razão de sua diversidade. Longe de ser um fenômeno institucional e centralizado, o que marca o movimento é a multiplicidade de ideias e práticas. Amurabi Oliveira (2011, p. 143-144) afirma que a Nova 
Era "nasce a partir de uma confluência de discursos e práticas, em especial, a partir do entrecruzamento do esoterismo europeu, e das religiões orientais”.

O nome Nova Era tem relação com a cosmologia astrológica e se refere a "mudança no aparente trajeto do sistema solar em relação ao zodíaco (...) estamos entrando em uma nova era, momento que sempre anuncia ou acarreta importantes modificações para a humanidade” (MAGNANI, 1999, p. 9-10). Essa Nova Era, conhecida como Era de Aquário, promete uma transformação na humanidade e colocaria em xeque os valores tradicionais da cultura ocidental, tais como as ideias tradicionais de Igreja, Estado, família e religião. Segundo alguns sujeitos inseridos dentro de práticas que podem ser consideradas Nova Era, a sociedade ocidental opõe natureza e civilização, dando maior destaque para a civilização. Essa situação causa impacto a todas as esferas da vida de um indivíduo, afastando da natureza seu corpo e psique (CAROZZI, 1999, p. 17).

A Era de Aquário tem ligação com o que os astrólogos chamam de Era Astrológica. Segundo nos explica o astrólogo e historiador Max Klim (2000) ${ }^{10}$, a Era Astrológica tem relação com o movimento de precessão da Terra ${ }^{11}$, um fenômeno astronômico que ocorre ao mesmo tempo que o movimento de rotação. A Terra não se encontra em um eixo reto, mas inclinada em torno de $23,5^{\circ}$ e é essa inclinação que gera o processo de precessão. Com essa leve inclinação, a Terra gira em torno do seu eixo inclinado e também de um "eixo imaginário vertical” - como um pião - caracterizando assim o fenômeno. A precessão possibilita a medição do tempo em milênios, com a Terra mudando a posição do polo magnético durante esse lento movimentar, representando assim, em astrologia, as Eras Astrológicas (KLIM, 2000, p. 22).

\footnotetext{
${ }^{10}$ Max Klim é o pseudônimo de Carlos Alberto Lemes de Andrade, um dos mais respeitados astrólogos do Brasil, responsável durante quatro décadas pelo horóscopo do Jornal do Brasil e de outros meios de comunicação.

${ }^{11}$ Esse trabalho não pretende uma longa explicação sobre o conceito de precessão da Terra. Para maiores informações, $\quad$ consulte $\quad \underline{\text { http://www.sbfisica.org.br/rbef/pdf/v21 507.pdf }}$ e http://astro.if.ufrgs.br/fordif/node8.htm, acesso em 28/07/2020.
} 


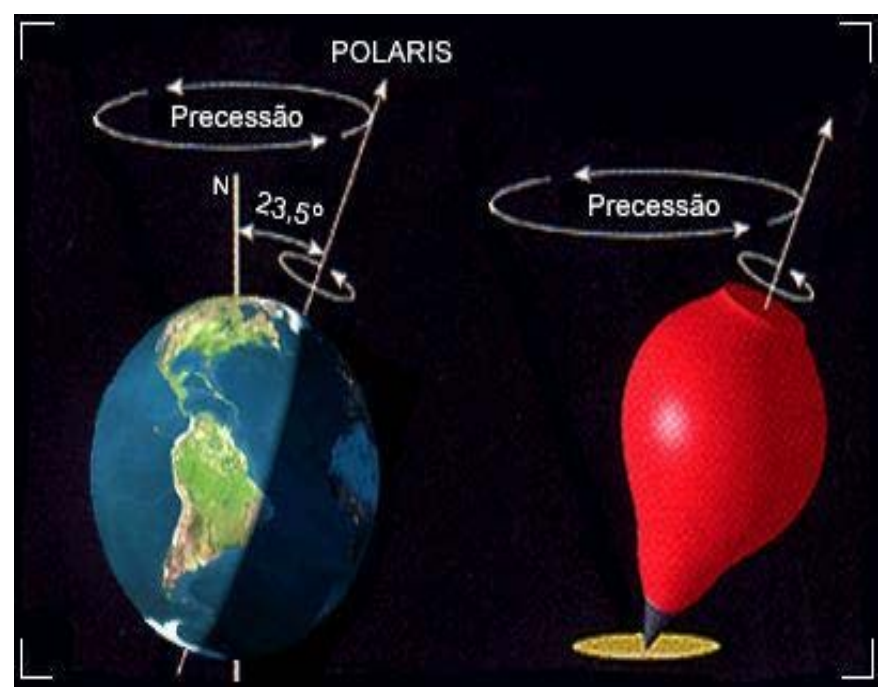

Imagem I - Movimento de Precessão

Fonte: http://astronomia-para-amadores.blogspot.pt/

Em astrologia, o Ciclo Astrológico - também conhecido como Ano Cósmico - se refere ao tempo total (aproximadamente 26 mil anos) que a Terra gira em torno do seu "eixo imaginário vertical”. Segundo Klim,

O movimento (...) coloca o nosso planeta sob a regência periódica dos signos do Zodíaco, da mesma forma como o ano é dividido em períodos aproximados de trinta dias, um para cada signo (...) A divisão dos Ciclos Astrais em 25.920 anos e em 12 Eras de 2.160 anos, cada uma com o nome de um signo, rege os diferentes períodos da história humana com lapsos de tempo nos quais a nossa espécie tem sido condicionada a agir em consonância com uma escala de valores que, de forma impressionante, representa a influência que os signos exercem sobre todos os seres humanos (KLIM, 2000, p. 23).

De acordo com o astrólogo, o ano de 1969 d.C. marcou a transição entre a Era de Peixes e a Era de Aquário, caracterizando assim uma nova Era Astrológica, onde a Terra estaria sob a influência da constelação de Aquário até 4.129 d.C. ${ }^{12}$

María Julia Carozzi (1999, p. 9) entende a Nova Era como um "fenômeno ao mesmo tempo social, cultural, religioso e terapêutico (...) constituído por uma rede internacional de indivíduos, majoritariamente habitantes urbanos do ocidente”. Essa rede tem suas origens históricas ligadas aos anos 60, em uma comunidade formada por diversas cabanas localizada

\footnotetext{
${ }^{12}$ A datação dos anos segue as referências de Klim. Outros astrólogos podem utilizar datações diferentes, mas os números são aproximados em 26.000 anos para o Ano Cósmico e 2100 anos para as Eras Astrológicas. Em relação ao início da Era de Aquário, alguns autores consideram a virada do século XX para o XXI como o momento de transição.
} 
em Esalen, Califórnia. ${ }^{13}$ Essa colônia tinha ligações íntimas com os movimentos contraculturais de sua época, se opondo às instituições ocidentais e ao progresso e muito interessados no oriente, em especial por sua religiosidade.

O grande ponto de virada dessa comunidade ocorre ainda nos anos 60, por influência de Michael Murphy, proprietário das terras de Esalen. Murphy decide abrir a colônia ao público, transformando-a em um projeto que oferece workshops, seminários e cursos ministrados por especialistas e grandes mestres orientais. Com essa abertura, existe uma grande busca de interessados em “distintas disciplinas à procura da ampliação da consciência e a atualização do próprio potencial” originando assim “uma rede de indivíduos que circulam por distintos centros e, em ocasiões, fundam os próprios, oferecendo suas sínteses pessoais de técnicas aprendidas” (CAROZZI, 1999, p. 12).

Wouter Hanegraaff (2005) propõe a divisão do movimento em duas partes: a Nova Era stricto sensu (1950-1970) e a Nova Era lato sensu (1980-1990). A Nova Era stricto sensu teria sua ligação ao interesse popular, em especial na Europa Ocidental e nos EUA, aos fenômenos OVNIs (objetos voadores não identificados) que ocorreram depois do fim da Segunda Guerra Mundial. Diversos grupos de estudo foram formados, muitos acreditando que essas espaçonaves eram tripuladas por seres evoluídos em sua cultura, tecnologia e espiritualidade, responsáveis por trazer uma Nova Era para a humanidade, salvando-a do apocalipse que o mundo moderno parecia construir. Como destacou o autor:

a Terra estaria entrando em um novo ciclo evolutivo que seria acompanhado por um
tipo novo e superior de consciência espiritual. Entretanto, visto que as culturas atuais
da humanidade foram completamente corrompidas pelo materialismo, elas resistiriam
a essa mudança. Como resultado, a transição para um novo ciclo de evolução
requereria a destruição da antiga civilização (...) resultando no colapso global
econômico, político e social. Os indivíduos cuja consciência já estivesse em sintonia
com as qualidades da nova cultura estariam protegidos de várias maneiras e
sobreviveriam ao período de cataclismos. No momento certo, tornar-se-iam a
vanguarda da Nova Era, da Era de Aquário: uma era de abundância, felicidade e
iluminação espiritual, quando a humanidade poderia mais uma vez viver de acordo
com as leis cósmicas universais (HANEGRAAFF, 2005, p. 2).

Durante os anos 60, na emergência da contracultura, as ideias dos grupos de estudo de OVNIs começam a circular em encontros de comunidades alternativas (HANEGRAAFF, 2005, p. 3) que, de acordo com Carozzi, tem como maior inspiração Esalen (CAROZZI, 1999, p. 12). É no entrecruzamento das concepções de salvação dos estudiosos de OVNIs com a busca da

\footnotetext{
${ }^{13}$ Maiores informações sobre Esalen podem ser obtidas em: https://www.esalen.org/ (acesso em 30 de julho de 2020 e em KRIPAL (2007).
} 
iluminação interior das comunidades alternativas que surgem diversos “centros de luz” no mundo, com destaque para a comunidade Findhorn ${ }^{14}$ na Escócia (HANEGRAAFF, 2005; CAROZZI, 1999).

Esses círculos adotam uma postura mais positiva, ativa e construtiva, deixando de lado o elemento apocalíptico dos grupos OVNIs para dar ênfase ao desenvolvimento da espiritualidade e harmonia, afirmando que a Nova Era estava em andamento. Desde então, esse tipo de pensamento tornou-se a proposta típica da Nova Era até o final dos anos 70 (HANEGRAAFF, 2005, p. 3). Nesse sentido, a Nova Era stricto sensu se caracteriza por "uma metafísica amplamente ocultista (...) uma ênfase relativamente forte nos valores comunitários e em uma moralidade tradicional enfatizando o amor altruísta e o serviço à humanidade” (HANEGRAAFF, 2005, p. 4).

A Nova Era surge, assim, como um fenômeno que tem ligação íntima com a contracultura e sua oposição ao ocidente. Ken Goffman e Dan Joy (2004) destacam a contracultura como um fenômeno multifacetado com a principal motivação de buscar a “afirmação do poder individual de criar sua própria vida”. Sendo muito mais do que uma rebeldia contra os valores da sociedade ocidental, é o apelo ao “individualismo compartilhado" que une os distintos grupos contraculturais. ${ }^{15}$ Os autores evidenciam três características em comum dentre esses sujeitos, destacando que procuram a “(...) individualidade acima de convenções sociais e restrições governamentais (...) desafiam o autoritarismo (...) defendem mudanças individuais e sociais” (GOFFMAN \& JOY, 2004, p. 5).

Esse individualismo não pode ser entendido como egoísmo, pois a contracultura visa, acima de tudo, a resistência ao autoritarismo. É a certeza que a mudança interna impacta o externo, atingindo um todo, que move a maioria desses movimentos - em especial, a Nova Era. Respeitando o individualismo, mas se colocando contra expressões individualistas que visam a opressão, os movimentos contraculturais promoveram uma mudança na sociedade ocidental, em especial nos EUA e no Reino Unido, agindo contra a Guerra do Vietnã, Guerra Fria, militando pelo feminismo, pela igualdade civil, contra o racismo, entre outros. Essa concepção de individualidade coaduna com diversas práticas e objetivos encontrados entre os adeptos da Nova Era.

No final da década de 70 e início da década de 80, o sucesso da Nova Era causou

\footnotetext{
${ }^{14}$ Para maiores informações sobre a comunidade Findhorn ver: www.findhorn.org, acesso em 30 de julho de 2020. 15 Sobre a diversidade da contracultura, GOFFMAN e JOY observam grupos que já foram definidos ou se autodefinem como contraculturais. Alguns exemplos: punks, hippies, clubbers, góticos, abraçadores de árvores, poetas performáticos, zen-budistas, adeptos da Nova Era, acadêmicos pós-modernos, entre muitos outros (2004, p. 3).
} 
transformações dentro do próprio movimento, caracterizando assim o surgimento do que Hanegraaff chama de Nova Era lato sensu. Tendo conhecimento de seu crescimento, grupos dentro da Nova Era começam “a se considerar parte de uma comunidade internacional invisível de indivíduos com pensamentos semelhantes, cujos esforços coletivos estavam destinados a transformar o mundo em um lugar melhor e mais espiritual” (HANEGRAAFF, 2005, p. 5).

A expressão Nova Era passa a ter um sentido mais vago, abarcando uma miríade de práticas espirituais, mais ou menos identificadas com a proposta de desenvolvimento espiritual e salvação comunitária. Esse “mercado espiritual”, que funciona de acordo com a lógica da sociedade capitalista (HANEGRAAFF, 2005, p. 10), procura satisfazer os anseios dos praticantes incorporando diversos novos elementos, tais como "sistemas divinatórios, propostas de autoajuda, técnicas de relaxamento e meditação (...) exercícios de yoga, tai-chi-chuan, lian gong; (...) o consumo de incenso e a crença em duendes” (MAGNANI, 1996, p. 7-8). São com essas diversas práticas que o sujeito procura despertar o seu “eu”, o self, conseguindo então atingir uma totalidade com o cosmos. Embora suas origens religiosas e místicas possam ser remetidas ao esoterismo e ocultismo desenvolvidos nos EUA e na Europa durante o século XIX (MAGNANI, 1999; HANEGRAAFF, 2005), apenas em contato com a contracultura tornou-se um movimento amplo que aos poucos obteve alcance mundial e certa coesão.

Silas Guerriero (2009) expõe que, no contexto de globalização, não existem religiões ou práticas “intocadas”, pois as fronteiras são fluídas e as trocas constantes. Tal dinâmica resulta em resistências e mudanças na religiosidade, ocorrendo assim a visibilidade de práticas religiosas de grupos étnicos ou locais bem específicos que agora são procurados por indivíduos dos centros urbanos ditos secularizados (GUERRIERO, 2009, p. 36). O autor explica que a Nova Era "resgata tradições, passadas e atuais. Com as passadas empreende um processo de recriação. Com as presentes, ressignifica-as” (GUERRIERO, 2009, p. 37). Nesse sentido, o movimento não promove um resgate "perfeito” das antigas religiosidades, ressignificando assim as religiosidades atuais e passadas.

Esse indivíduo da Nova Era, a partir do momento que busca transformar a si mesmo, objetiva também influenciar o mundo ao seu redor. Ele se coloca em um eterno estado de vira-ser, pois o caminho da espiritualidade não almeja encontrar um fim, sendo a própria busca o fim em si (AMARAL, 1999, p. 75). Para encerrar, as palavras de María Contepomi (1999) são esclarecedoras:

A proposta de transformação da Nova Era - símbolo central de seu universo simbólico - assenta-se no indivíduo, locus excludente de uma revolução estabelecida a partir e ao interior do sujeito. O indivíduo é o princípio e centro da metamorfose que compreende o universo pessoal como um todo e do qual, 
por efeito multiplicador, expandir-se-á no mundo exterior (CONTEPOMI, 1999, p. 136).

\section{O “DESPERTAR” ATEÍSTA: MORALIDADE E ESPIRITUALIDADE NO COMBATE AO “ABISMO” RELIGIOSO}

Ao que tudo indica, foi Harris que desencadeou um amplo movimento de ataque antirreligioso organizado pelos ateus ao lançar O Fim da Fé em $2004^{16}$ - conhecido no meio acadêmico e mídia como “neo-ateísmo”. O próprio autor afirma que a obra começou a ser escrita um dia depois dos atentados de 11 de setembro de 2001, onde membros da organização islâmica Al-Qaeda colidiram aviões contra as Torres Gêmeas e o Pentágono - tentou-se atacar o Capitólio, mas o avião caiu antes de cumprir seu objetivo.

Slavoj Zizek (2003) analisou a repercussão e mobilização do governo norte-americano depois dos atentados. Segundo o autor, o evento foi impactante mais pelo seu efeito espetacular do que pelos danos materiais que causou (ZIZEK, 2003, p. 26). Os atentados deixaram os EUA em um "permanente estado de catástrofe”, com o governo mobilizando o ocorrido como justificativa para coordenar “ataques preventivos” ao oriente médio, finalmente recuperando suas intervenções armadas em outros países após o longo trauma causado pela derrota na Guerra do Vietnã (ZIZEK, 2003, p. 13). De acordo com o autor,

o estado em que vivemos hoje, da "guerra ao terror”, é o estado da ameaça terrorista eternamente suspensa: a Catástrofe (novo ataque terrorista) é considerada certa, mas ela é indefinidamente adiada - o que vier a acontecer, ainda que seja um ataque muito mais horrível do que o de 11 de setembro, não será “aquele” (ZIZEK, 2003, p. 12).

Essas intervenções, de acordo com Zizek, encontram apoio em parte da opinião pública norte-americana, fato refletido em O Fim da Fé. Harris afirma diversas vezes sua preocupação com armas de destruição em massa serem adquiridas pelos grupos ditos terroristas que, motivados pelas práticas ensinadas pelo islamismo, poderiam causar uma catástrofe que ameaçaria o futuro da humanidade. Harris defende o governo norte-americano em suas intervenções armadas, argumentando que “as pessoas tolerantes poderão ter de as matar [os terroristas] em legítima defesa. Foi isto que os Estados Unidos tentaram fazer no Afeganistão, e é isto que nós, bem como outras potências ocidentais, seremos certamente obrigados a fazer” (HARRIS, 2007, p. 58).

\footnotetext{
${ }^{16}$ Após o lançamento da obra de Harris, diversos livros de cientistas ateus foram publicados, tornando-se bestsellers no mundo inteiro. Nesse sentido, podemos destacar The God Delusion (2006), de Richard Dawkins e Breaking the Spell: Religion as a Natural Phenomenon (2006) de Daniel Dennett.
} 
Em relação ao "neo-ateísmo”, o nome foi cunhado em 2006, quando a revista Wired publicou uma matéria intitulada The church of the non-believers ${ }^{17}$, destacando os cientistas Richard Dawkins, Sam Harris e Daniel Dennett ${ }^{18}$ como os "novos ateístas”, homens que desafiam a religião de maneira direta e politizada. Depois dessa matéria, o termo "neo-ateísmo" ou “Novo Ateísmo” passou a ser usado com frequência para retratar a diversas manifestações antirreligiosas ateístas que surgiram com a influência dessas e de outras obras dos autores. ${ }^{19}$

O “neo-ateísmo” não é apenas um ataque desorganizado contra a religião, mas um movimento militante maior e de alcance mundial (MOREIRA, 2014; FRANCO, 2014). Leonardo Moreira (2014) destaca que o movimento se caracteriza por não estar vinculado a uma obra ou autor, mas a uma grande quantidade de pessoas que defendem o ateísmo de maneira politizada e pública. Clarissa de Franco (2014) enumera cinco fatores para demonstrar que existe um movimento em curso:

1) Característica de movimento social; 2) estado secular que dá proteção e força aos ateus, relegando os religiosos para o lugar da obsolescência; 3) passagem do paradigma filosófico para o científico na defesa do ateísmo, com penetração pelo senso comum; 4) cenário de terrorismo religioso, que assustou o mundo com mais intensidade desde 11/09/01, e 5) internet, que possibilita a formação de redes e o espraiamento das ideias ateístas, focando o público jovem (FRANCO, 2014, p. 13). ${ }^{20}$

No Brasil, o representante mais destacado do “neo-ateísmo” é a Associação Brasileira de Ateus e Agnósticos (ATEA), entidade que tem como principal objetivo lutar pela laicidade do Estado e contra os preconceitos sofridos por ateus. As afirmações antirreligiosas de Harris encontram eco em diversos posicionamentos da associação, que também interpretam a religião como maléfica em si, sinal de atraso e passível de permitir diversas atrocidades de seus fiéis. Além disso, diversos materiais de divulgação e publicação da associação estampam o rosto de Harris e dos outros autores “neo-ateus”. Sua atuação ao longo dos últimos anos a credenciam como o primeiro movimento social ateísta brasileiro (FIRMINO, 2018).

\footnotetext{
${ }^{17}$ Matéria disponível em: https://www.wired.com/2006/11/atheism/, acesso em 23 de julho de 2020.

${ }^{18}$ Posteriormente, juntou-se ao grupo o jornalista inglês Christopher Hitchens, lançando a impactante obra Deus não é grande: como a religião envenena tudo (2007). Os quatro autores ficaram conhecidos como "Os Quatro Cavaleiros do Ateísmo" depois de gravarem o vídeo The Four Horsemen (2007), onde discutem sobre ateísmo, ciência e religião. Hitchens faleceu em 2011 devido a um câncer do esôfago. Antes de sua morte, escreveu os livros Hitch 22 (2011), sua biografia e Últimas Palavras (2011), que conta a evolução de seu câncer e como aceitar essa condição de maneira racional e moderada. Para maiores informações sobre o vídeo The Four Horsemen ver FIRMINO (2018).

${ }^{19}$ É importante notar que o termo "neo-ateísmo" ou “neo-ateu” não é utilizado pelas instituições e grupos ateístas da contemporaneidade, sendo considerado pejorativo (FRANCO, 2014, p. 12). 
Em O Fim da Fé, Harris afirma que a fé deve ser criticada como qualquer outro assunto do interesse humano, sendo necessário acabar com a aparente “imunidade” que a mesma tem em relação à crítica racional (HARRIS, 2007, p.15). A crença religiosa é irracional e maléfica ao gênero humano, sendo um grande entrave ao progresso e evolução da sociedade como um todo, em especial da ciência e da razão.

Harris entende que existe uma dimensão espiritual na vida do indivíduo que a ciência ainda não consegue compreender claramente. A grande questão é que a procura por essas respostas são encontradas pelos religiosos em textos antiquíssimos que não podem ter suas afirmações comprovadas empiricamente (HARRIS, 2007, p. 18). Não é a busca que o incomoda, mas o local e as consequências dessa procura em religiões que o mesmo considera irracionais e violentas. É nesse sentido que Harris debate a importância da racionalidade na construção da moralidade e na investigação da espiritualidade humana. Sobre textos religiosos como a Bíblia e o Alcorão, argumenta que é:

um erro pensar que esses textos conservaram a sua integridade ao longo do tempo; simplesmente, foram difundidos omitindo-se algumas das suas passagens. A maior parte daquilo que sobra (...) só escapou da triagem porque ainda não dispomos de uma compreensão verdadeiramente moderna das nossas intuições éticas e da nossa capacidade de experiência espiritual (...) Estas são, em última análise, questões a levantar por uma ciência do espírito madura. Se alguma vez conseguirmos desenvolver tal ciência, a maioria dos nossos textos religiosos serão tão úteis para os místicos como hoje o são para os astrônomos (HARRIS, 2007, p. 22).

Nesse sentido, a ciência pode invalidar as afirmações dos textos sagrados, bem como eliminar a influência religiosa do mundo. É interessante notar que, para Harris, a moderação religiosa é um fruto do crescimento da ciência e da secularização na medida que os religiosos são obrigados a reinterpretar os textos sagrados para se acomodar ao progresso humano em campos como a ciência, política e direitos humanos (HARRIS, 2007, p. 21). Segundo o autor, os moderados são filhos do conhecimento secular ou apenas ignorantes diante dos seus próprios textos sagrados, sendo vistos como sinal de fraqueza e afastamento das escrituras pelos religiosos mais extremistas. Além disso, a moderação religiosa é um grande problema, pois "fecha a porta a outras abordagens mais sofisticadas da espiritualidade, ética e da construção de comunidades fortes” (HARRIS, 2007, p. 23).

Para o autor, a religião se trata de uma série "superstições e tabus antigos (...) um sistema de crenças que nos foi legado por homens e mulheres cujas vidas foram arruinadas devido a uma ignorância elementar sobre as coisas do mundo” (HARRIS, 2007, p. 24). O medo da morte, 
para Harris, é o principal elemento na criação e manutenção das crenças religiosas e a possibilidade de continuar "existindo" mesmo depois de morrer o argumento religioso mais forte. O neurocientista afirma que a crença do indivíduo sobre que pode ocorrer depois de morrer determina muito daquilo que ele acredita em vida e "sem a morte, a influência da religião baseada na fé seria impensável” (HARRIS, 2007, p. 42).

Harris argumenta que cérebro humano é capaz de criar as mais diversas crenças sobre o mundo, julgando afirmações com base em verdades já aceitas. A aceitação ou não de determinadas crenças tem relação com a capacidade de agir e tomar decisões. Para o autor, “crenças são princípios de acção (...) processos através dos quais o nosso entendimento (e desentendimento) do mundo é representado e validado para orientar nosso comportamento" (HARRIS, 2007, p. 57). Nesse sentido, a crença é um fruto da evolução, sendo responsável por ações que tomamos, influenciando de forma decisiva as emoções.

Existe um elo poderoso entre crença e comportamento e é nesse sentido que algumas crenças são tão perigosas. Segundo afirma Harris, diversas crenças consideram ético matar desde que esteja dentro do escopo do que o indivíduo acredita. Dessa forma, as crenças religiosas são um perigo em potencial pela sua irracionalidade inerente e o apego a um passado onde as afirmações não eram esclarecidas pela razão. Para o autor, as crenças precisam de uma coerência lógica na medida que afirmam verdades ou mentiras sobre um objeto, não podendo ser contraditórias. Segundo o exemplo do mesmo, “o telefone toca... ou é meu irmão (...) ou não é (...) Posso acreditar numa proposição ou na outra - ou então posso acreditar que não sei - mas em circunstância alguma seria aceitável que eu acreditasse em ambas” (HARRIS, 2007, p. 59). Harris afirma:

\footnotetext{
“(...) num sentido epistêmico - isto é, a crença que aspira a representação nosso conhecimento do mundo - exige que acreditemos na autenticidade de uma dada proposição, e não apenas no desejo de que assim seja (...) Por que razão será um erro acreditar que uma proposição é verdadeira só por causa de ela nos fazer sentir bem? Basta determo-nos no significado da locução "por causa” para perceber o problema (...) "por causa" sugere uma conexão causal entre o facto de uma proposição ser verdadeira e o facto de uma pessoa nela acreditar. Isto explica o valor que normalmente atribuímos à evidência empírica: porque esta é apenas o testemunho da ligação causal entre os estados do mundo e as nossas crenças sobre eles” (HARRIS, 2007, p. 67).
}

Assim sendo, as crenças religiosas não podem dizer nada sobre a realidade porque suas afirmações e relações entre causa e efeito não podem ser comprovadas empiricamente. Segundo o autor, “Acreditar que Deus existe é acreditar que eu mantenho com a sua existência uma relação tal que a sua existência é em si mesma a razão da minha crença” (HARRIS, 2007, p. 
68). Apenas quando as crenças religiosas seguirem os mesmos critérios comprovatórios como quaisquer outras crenças será possível que tenha algum crédito - como por exemplo, demonstrar empiricamente que Deus consegue ouvir as orações.

Nesse sentido, o autor afirma que “todo projecto religioso se afigura retrógrado, já que não consegue resistir às mudanças que se operaram em nós - culturalmente, tecnologicamente e até eticamente” (HARRIS, 2007, p. 25). O sagrado seria um fruto do passado, sendo por isso a religião perigosamente anacrônica, pois “ a fé religiosa simboliza a má aplicação que é possível dar ao poder da inteligência (...) ela forma uma espécie de singularidade cultural perversa - um ponto de fuga para além do qual o discurso da razão deixa de fazer sentido” (HARRIS, 2007, p. 28). Para o autor, a fé se trata de uma

crença injustificada em assuntos de extrema importância - especificamente em proposições que prometem um qualquer mecanismo através do qual a vida humana pode ser poupada à inclemência do tempo e da morte. A fé é aquilo em que a credulidade se transforma quando finalmente consegue escapar aos constrangimentos do discurso terrestre - constrangimentos esses como a racionalidade, a coerência interna, a civilidade e franqueza (...) a ignorância é a verdadeira moeda desse reino (HARRIS, 2007, p. 70-71).

O autor divide os religiosos em dois grupos, os “crentes extremistas” e os “crentes moderados” e afirma que seu livro não foi endereçado aos extremistas, pois esses não entendem a linguagem da diplomacia e da ponderação. O seu alvo principal são os religiosos moderados que, de acordo com Harris, "imaginam que o caminho para a paz só será desbravado quando cada um de nós tiver aprendido a respeitar as crenças injustificadas dos outros”. Para o autor, é justamente esse “respeito a irracionalidade” que levará a humanidade para o abismo. (HARRIS, 2007, p. 17). O abismo citado por Harris diz respeito ao fato das crenças religiosas possibilitarem inúmeras atrocidades em nome da fé.

O neurocientista afirma que tais crenças tendem a fazer com que os seres humanos matem uns aos outros, sendo o tema que oferece a maior possibilidade da humanidade se aniquilar (HARRIS, 2007, p. 15). Segundo o autor, todas as crenças religiosas têm um caráter destrutivo e o futuro da humanidade depende do fim das mesmas. De acordo com o mesmo,

Se não conseguirmos encontrar uma maneira ou um tempo em que a maioria de nós esteja disposta a admitir, no mínimo, que não podemos ter a certeza se Deus escreveu ou não alguns dos nossos livros, então, resta-nos apenas contar os dias até ao Armagedão - porque Deus deu-nos muito mais razões para nos matarmos uns aos outros do que para oferecermos a outra face (HARRIS, 2007, p. 38). 
A fé religiosa é tão aceita, argumenta Harris, pelo fato de garantir algo desejável no futuro - como por exemplo, garantir um lugar melhor depois de morrer (HARRIS, 2007, p. 75). Porém, é justamente a garantia de que existe um “paraíso” que motiva os crentes a atos violentos e irracionais. Segundo defende Harris, o fato do crente não temer o destino depois de morrer que motiva os extremismos como guerras religiosas e o terrorismo. A fé, afirma, é a mãe do ódio (HARIS, 2007, p.33). A humanidade se aniquilará se as crenças religiosas não tiverem um fim e o atentado do 11 de setembro é um exemplo claro dessa afirmação.

A ideia de um apocalipse vindouro é comum a vários grupos considerados pertencentes ao movimento Nova Era. O homem da Era de Aquário, desejoso de uma transformação na sociedade e em si próprio, busca superar esse apocalipse com novas práticas, como mencionado anteriormente no artigo. Isto posto, é possível encontrar em Harris a mesma preocupação com o fim da humanidade ou um colapso global.

Nesse sentido, tanto para alguns círculos Nova Era quanto para Harris, a humanidade caminha para o abismo, sendo o apocalipse uma questão de tempo se nada for mudado. É necessário, para ambos, uma nova moral e formas de lidar com a espiritualidade que as crenças religiosas tradicionais, em especial as monoteístas, não obtiveram sucesso. Assim sendo, enquanto alguns adeptos da Nova Era reinterpretam as religiões tradicionais na procura pela salvação ${ }^{21}$, Harris encontra a possibilidade do desenvolvimento moral e espiritual baseado em evidências empíricas para tal feito. A procura é a mesma, o destino também, mas em Harris qualquer elemento sobrenatural é eliminado nessa busca.

A Paisagem Moral objetiva não apenas reforçar o discurso antirreligioso exposto em $O$ Fim da Fé, mas propõe uma moralidade baseada totalmente na ciência moderna. Segundo o neurocientista, conforme o conhecimento racional se aprimora, maior a capacidade do ser humano agir de maneira moral. Nesse sentido, como o autor considera o discurso religioso irracional por natureza, a ciência deve ser considerada o único critério válido nas tomadas de decisões da sociedade. Seu argumento central é: não é necessário um deus para buscar o bemestar da humanidade, pois a mesma pode fazer isso agindo de maneira racional e se preocupando com o próximo.

Harris procura demonstrar como é possível a ciência ter conclusões objetivas sobre moral e valores. Embora o estudo da moralidade seja considerado pelo mesmo como um campo ainda em desenvolvimento na ciência, destaca que, com pesquisas sérias e honestidade intelectual, esse fator pode ser mudado. Um grande problema, argumenta Harris, é que parte da sociedade

${ }^{21}$ VER CAMURÇA e CAMPANHA (2016) e o caso da comunidade Ordem Graça Misericórdia, que transitam entre Ufologia e Catolicismo na busca de sua salvação. 
acredita que os valores e a moral só ocorrem devido a algum preceito religioso. Pela ligação estreita entre o governo e religião, em especial nos EUA, muitos cientistas procuram não intervir nessas questões, muitos com receio de seus fundos de pesquisa serem cortados. Dessa forma, entendem a moralidade como um assunto que não deve ser estudado cientificamente (HARRIS, 2013, p. 14).

Discordando dessa proposta, o autor afirma que a moral pode e deve ser estudada pela ciência, e um caminho para isso é estabelecer uma conexão entre moral e bem-estar. Para o autor, a moralidade é definida como "o conjunto de atitudes, escolhas e comportamentos que potencialmente afetam a felicidade e o sofrimento de outras mentes conscientes" (HARRIS, 2013, p. 20). E, embora aceite que estabelecer o conceito de "bem-estar" seja problemático (HARRIS, 2013, p. 19), isso não impede que o mesmo seja estudado.

Harris acredita que a possível dificuldade em estudar objetivamente os valores humanos reside, principalmente, devido a uma afirmação que considera intelectualmente insustentável, que diz respeito às possíveis diferenças entre valores e fatos. Segundo argumenta Harris, fatos e valores não possuem diferenças, em especial no ponto de vista da neurociência (HARRIS, 2013, p. 31). Segundo o autor,

\begin{abstract}
O cérebro humano é uma máquina de acreditar. Nossas mentes constantemente consomem, produzem e tentam integrar ideias sobre nós mesmos e sobre o mundo à nossa volta que se propõem verdadeiras (...) a crença também faz a ponte entre fatos e valores. Nós formamos crenças sobre fatos, e, nesse sentido, a crença perfaz a maior parte daquilo que sabemos sobre o mundo (...) mas também formamos crenças sobre valores (...) ambos os tipos de crença fazem alegações tácitas sobre certo e errado: alegações estas que não se limitam àquilo que pensamos e sentimos, mas também àquilo que deveríamos pensar e sentir (HARRIS, 2013, p. 22).
\end{abstract}

Nesse sentido, acredita que a neurociência pode compreender os valores da mesma forma que compreende os fatos, pois ambos são processados pelo cérebro. O que falta, segundo Harris, é o desenvolvimento da pesquisa acadêmica objetiva no campo da moral, pois assim seria possível verificar como a fronteira entre fatos e valores é ilusória (HARRIS, 2013, p. 22), sendo possível perseguir uma verdade moral. Para que sejam criadas essas “leis morais”, seriam necessários então especialistas, pois "somente especialistas genuínos em moralidade teriam uma compreensão profunda das causas e das condições do bem-estar (...) precisamos de um parâmetro que defina o que é “certo” e "errado” ao falarmos de física ou de moral (...)” (HARRIS, 2013, p. 42).

A discussão e interpretação de moral proposta acima é importante para entendermos uma das ideias mais relevantes de Harris, que é a desconstrução do conceito de self, conhecido 
também como eu. Nesse sentido, o autor acredita ser possível um estudo científico da espiritualidade, desde que sejam afastadas ideias religiosas e místicas.

Harris define experiência espiritual como “experiências de sentido, de esvaziamento do $e u$ e de elevada intensidade emocional que ultrapassam os limites estreitos das nossas identidades enquanto eus e escapam ao entendimento comum da mente e do cérebro" (HARRIS, 2007, p. 43). É nesse sentido que o autor entende ser possível entender a espiritualidade de maneira racional, pois é como qualquer experiência, possuindo relação com o mundo, evoluindo com o conhecimento que o ser humano obtém. Harris considera um engano entender tais experiências como místicas, sendo consideradas "espirituais” ou "místicas” apenas à falta de melhores termos (HARRIS, 2007, p. 43). Entendendo "espiritual” como "os esforços que as pessoas fazem, através da meditação, substâncias psicodélicas ou de outros meios, para trazer a mente por inteiro ao presente ou para induzir estados incomuns de consciência” (HARRIS, 2015, p. 15), o autor pretende uma “abordagem racional da espiritualidade”, procedendo dessa maneira em Despertar.

Na obra Despertar, Harris procura esclarecer a proposta de "espiritualidade sem religião” em concordância com sua militância antirreligiosa. Essa obra age em duas direções: (1) demonstrar como as “experiências espirituais” são apenas processos neuroquímicos do cérebro, sendo por isso explicáveis pela ciência; (2) ser o guia para o desenvolvimento de uma “espiritualidade sem religião”, buscando demonstrar como é possível a mente humana influir no corpo de maneira direta sem a necessidade de nenhum traço dito sobrenatural. O caminho para que isso ocorra é através da meditação e pelo uso de algumas drogas que fazem o cérebro atingir estágios específicos - dois elementos recorrentes em círculos da Nova Era.

Guerriero sugere que “as práticas que costumam ser classificadas como de Nova Era são a ponta de um iceberg, a parte visível de um estilo diferente de lidar com a espiritualidade, com o corpo e com o desenvolvimento pessoal” (GUERRIERO, 2009, p. 38 [grifo nosso]). A tríplice busca destacada por Guerriero - as formas de lidar com a espiritualidade, com o corpo e com o desenvolvimento pessoal - encontram-se presentes nas ideias de Harris. O autor ateu procura demonstrar que esses três aspectos podem ser alcançados por um ateu de maneira plena através da moral guiada pela ciência, meditação e da espiritualidade.

De acordo com Guerriero, a Nova Era parte do pressuposto de que a “divindade” está dentro de cada um, colocando-a como a “religião do self” (GUERRIERO, 2009, p. 9). A ideia de self é recorrente nos estudos sobre o fenômeno, sendo central nessa discussão. O self é o ser, nossa identidade, nosso lugar no mundo. De acordo com Charles Taylor (1997), um dos sentidos ao se referir a uma pessoa como self significa dizer que “elas são seres da profundidade 
e complexidade necessárias para ter (ou para estar empenhadas na descoberta de) uma identidade” (TAYLOR, 1997, p. 50).

Para Harris, essas experiências revelam a natureza da nossa própria consciência e do nosso psique, tendo que ser compreendidas nos termos da ciência moderna. Para entender sobre a natureza humana é necessário se livrar dos dogmas que ligam a moralidade com a religião, sendo a ciência o único caminho de investigação confiável (HARRIS, 2015, p. 17-18). É no sentido de compreender que o self é uma ilusão que o autor introduz a meditação e o seu estudo científico. A meditação, para o autor, leva diretamente à dissipação do self:

o sentimento que chamamos de “eu” é uma ilusão. Não existe um self ou ego distinto (...) e a sensação de que ele existe - a ideia de que você se encontra em algum lugar atrás de seus olhos, olhando para um mundo destacado de você - pode ser alterada ou completamente extinta. Embora as experiências de "autotranscedência” costumem ser interpretadas em bases religiosas, não há nelas, em princípio, nada de irracional (...) “espiritualidade” significa o aprofundamento da compreensão e a indicação reiterada da ilusão representada pelo self (HARRIS, 2015, p. 17-18).

Conforme expõe o neurocientista, esse estado mental é difícil de atingir e de estudar pelo fato das crenças religiosas nublarem a potencialidade da mente humana, pois obrigam o cérebro humano a acreditar em uma série de superstições e falácias que dificultam o nosso entendimento sobre o assunto (HARRIS, 2015, p. 24). A espiritualidade age no sentido de possibilitar a felicidade ao gênero humano, e isso ocorre no momento em que as ilusões do self são apagadas. De acordo com Harris, “(...) um praticante espiritual verdadeiro é alguém que descobriu que é possível estar satisfeito no mundo sem razão nenhuma (...) e que tal satisfação é sinônimo de transcender as fronteiras aparentes do self” (HARRIS, 2015, p. 26).

Embora relacionado usualmente com a experiência religiosa, a espiritualidade, de acordo com a Organização Mundial de Saúde (OMS), tem ligação com o bem-estar, não possuindo exatamente um caráter sobrenatural ou místico. De acordo com Sandra Volcan et al (2003), em 1988 a OMS incluiu a espiritualidade no conceito multidimensional de saúde, definindo-a como:

o conjunto de todas as emoções e convicções de natureza não material, com a suposição de que há mais no viver do que pode ser percebido ou plenamente compreendido, remetendo a questões como o significado e sentido da vida, não se limitando a (...) crença ou prática religiosa (VOLCAN et al, 2003, p. 441).

Dessa forma, a espiritualidade se desloca do seu sentido religioso, podendo ser alcançado por qualquer indivíduo, mesmo os ateus. Franco demonstrou a possibilidade do desenvolvimento de uma "espiritualidade laica”, estudando filósofos ateus contemporâneos 
como Luc Ferry e André Comte-Sponville. Na perspectiva de Franco, a espiritualidade laica se coloca como

uma prática ou uma posição ideológica que, embora rejeite a ideia de Deus e deuses, de sobrenatural, de elementos identificados com pensamento mágico e religioso, apontam para uma vivência de significados emocionais profundos, que envolvem elementos como solidariedade, compaixão, ética, bem-estar, aprimoramento do ser, da humanidade e do mundo, integração e conexão do indivíduo com o cosmos (FRANCO, 2015, p. 102).

Para que a espiritualidade almejada por Harris ocorra, o autor procura "desencantar" práticas relacionadas com a Nova Era, tais como a meditação e o uso de drogas para fins místicos. Segundo Odair Araújo (2003, p. 2), “o processo de desencantamento caracteriza-se pela racionalização das atividades religiosas”. Essa ideia, desenvolvida inicialmente por Max Weber (2013), defende que, com a desvalorização dos sacramentos por seitas de origem protestante, em especial as calvinistas e batistas, foi imposto um estilo de vida e visão racional da realidade, desmistificando um mundo considerado “encantado”. Dessa maneira, “a ética puritana ascética acaba provocando também o desencantamento e racionalização do mundo. As ações orientar-se-iam (...) ainda que não plenamente, por uma instrumentalização moderna” (ARAÚJO, 2003, p. 3).

Enquanto o desencantamento do mundo é um processo de interpretação racional da realidade, colocando em dúvida um universo permeado pelo sobrenatural, a secularização ocorre em razão dessa racionalização, no sentido que a religião deixa de ser a única doadora de sentido na vida da sociedade moderna. Nas palavras de Antônio Pierucci (1998, p.9), a secularização "nos remete à luta da modernidade cultural contra a religião, tendo como manifestação empírica o mundo moderno e o declínio da religião como potência”. Isso não significa afirmar que ocorrerá o "fim da religião", mas que parte do sentimento religioso se desloca do público para o privado.

Segundo a socióloga Danièle Hervieu-Léger (2015), a religião na sociedade ocidental contemporânea perdeu seu status de doadora hegemônica de sentido, pois nenhuma autoridade é capaz de impô-la em esfera pública. Nesse sentido, a religião, mesmo as institucionais e com maior poder, precisam lidar com questões como liberdade religiosa, laicidade do Estado, entre outros. Essa falta de controle rígido que havia outrora, tanto de seus fiéis quanto do Estado, provoca a difusão de um “crer” individualista, promovendo a "generalização de uma busca espiritual que toca, sob formas diversas, todas as camadas da sociedade” (HERVIEU-LÉGER, 2015, p. 115). 
Diante dessa descentralização e do controle institucional não ser tão eficaz como nas sociedades feudais e do Antigo Regime, por exemplo, a "generalização de uma busca espiritual” não ocorre apenas com grupos religiosos ou “místicos”, mas também entre indivíduos ateus. É no desenvolvimento desta nova espiritualidade, calcada nas evidências empíricas da ciência moderna, que Harris acredita ser possível “salvar mundo das trevas da ignorância religiosa”.

Assim sendo, a “espiritualidade ateísta” de Harris surge do “desencantar” de práticas que pertencem a Nova Era. Isso “permite” ao sujeito ateu, mesmo que seja radical em sua militância antirreligiosa, o ingresso nas experiências espirituais típicas da contemporaneidade, descentralizadas, sem nenhum vínculo institucional, sendo inclusive supostamente esclarecidas pela ciência moderna, afastando seu teor religioso e místico.

\section{CONCLUSÕES PRELIMINARES}

Embora o artigo apresentado seja um recorte da tese de doutorado ainda em andamento, algumas conclusões preliminares podem ser consideradas. Retomando às questões propostas na introdução deste artigo, é possível responder, ao menos parcialmente, as questões elencadas: (1) assim como a Nova Era consegue influenciar, reinterpretar e ressignificar as crenças religiosas contemporâneas com práticas místicas/sobrenaturais que visam o bem-estar do indivíduo, a proposta de Harris não pode ser considerada pertencente ao que chamamos de Nova Era? (2) As reflexões de Harris podem ser um sinal das ressignificações da Nova Era no ateísmo, com práticas consideradas místicas “desencantadas” com a intenção que sejam praticadas até mesmo por um ateu militante com a “consciência tranquila”? (3) Estaríamos presenciando, com Harris, o surgimento de um “Ateísmo New Age”?

Em relação ao ponto (1), a pesquisa esclarece que da mesma forma que a Nova Era consegue reinterpretar as crenças religiosas, pode também fazer com as práticas ateístas da contemporaneidade. De maneira similar às vivências espirituais dos praticantes da Nova Era caminha a espiritualidade ateísta de Harris, utilizando para isso a meditação, drogas psicodélicas e ensinamentos derivados da cultura oriental. Assim como o amplo conjunto de experiências chamadas de Nova Era, coloca o indivíduo no centro da busca pelo desenvolvimento espiritual, de maneira individual, reinterpretando e racionalizando o sentido de self, mas ainda dentro da proposta New Age. A busca pela salvação em um mundo na beira de um apocalipse causado pelas crenças religiosas é uma preocupação constante do autor, que entende os atentados de 11 de setembro como um aprova das atrocidades cometidas em nome da fé. 
A possibilidade de “desencantamento” proposto no ponto (2) parece ocorrer de maneira constante, conforme o autor pauta sua observação na ciência moderna. Tanto a tentativa de propor uma moralidade e espiritualidade afastadas da religiosidade encontram eco em sua militância antirreligiosa e ateísta. Com sua proposta “desencantadora”, promove a entrada de um grande número de indivíduos ateus que, talvez por não querer se relacionar com uma atividade considerada mística, agora podem ter contato com um sem número de práticas sem que para isso tenha de abandonar sua "racionalidade".

Quanto ao item (3), logicamente essa abordagem preliminar não pretendia responder, sendo uma das hipóteses principais da tese de doutorado. Porém, as observações de Harris que veremos a seguir demonstram como o mesmo se preocupa com essa situação:

É por certo inconveniente para as forças da razão e do secularismo que, se alguém acordar amanhã sentindo um amor ilimitado por todos os seres sencientes, as únicas pessoas que provavelmente reconhecerão a legitimidade da experiência desse indivíduo serão representantes de uma ou outra religião da Idade do Ferro ou de um culto new age (HARRIS, 2015, p. 23).

Embora afirme que suas ideias se afastam do “culto new age” e que pretende "extrair o diamante do monturo da religião esotérica” (HARRIS, 2015, p. 19) essa explanação inicial encontrou indícios que podem contrariar a afirmação do autor. A hipótese que se coloca, de agora em diante, é investigar se a Nova Era consegue ressignificar o ateísmo de Harris a ponto de ser possível compreender as ideias do autor como um "Ateísmo New Age”.

\section{REFERÊNCIAS BIBIOGRÁFICAS}

ALMEIDA, Fabio Chang de. O historiador e as fontes digitais: uma visão acerca da área da internet como fonte primária para pesquisas históricas. AEDOS. Revista do corpo discente do PPG-História da UFRG. Num.8, vol. 3, Janeiro - Junho 2011.

AMARAL, Leila. Sincretismo em movimento - O estilo Nova Era de lidar com o sagrado. IN: A Nova Era no Mercosul. Rio de Janeiro, Petrópolis, Vozes: 1999.

ARAÚJO, Odair José de. "Secularização e efervescência religiosa: contrastes da modernidade”. XI Congresso Brasileiro de Sociologia. UNICAMP, Campinas, SP, GT 19: Religião e Sociedade. 1 a 5 de setembro de 2003, pp: 1-14.

CARDOSO, Ciro; VAINFAS, Ronaldo. História e análise de textos. IN: Domínios da História: ensaios de teoria e metodologia. Rio de Janeiro: Campus, 1997

CAROZZI, María Julia. Introdução. IN: A Nova Era no Mercosul. Rio de Janeiro, Petrópolis, Vozes: 1999. 
CONTEPOMI, María. Nova Era e Pós-Modernidade: Valores, crenças e práticas no contexto sociocultural contemporâneo. IN: A Nova Era no Mercosul. Rio de Janeiro, Petrópolis, Vozes: 1999.

FRANCO, Clarissa de. $\mathbf{O}$ ateísmo de Richard Dawkins nas fronteiras da ciência evolucionista e do senso comum. Tese de Doutorado. PUC, São Paulo, 2014.

Ateísmo contemporâneo e celebração da ética do bem-estar: elementos festivos da espiritualidade ateia. IN: Ciberteologia - Revista de Teologia \& Cultura - Ano XI, 2015.

GOFFMAN, Ken \& JOY, Dan. Definindo Contracultura. IN: Contracultura através dos tempos. (versão digital do capítulo 2 disponível em:

https://pt.scribd.com/document/26758728/DefinindoContracultura-Ken-Goffman-e-Dan-Joy) acesso em: 29/07/2020.

GUERRIERO, Silas. Novas configurações das religiões tradicionais: re-significação e influência do universo Nova Era. IN: Tomo, Sergipe: São Cristóvão, n14, 2009.

HANEGRAAFF, Wounder. New Age Movement. IN: JONES, Lindsay (Org.). IN:

Encyclopedia Of Religion. 10 v. $2^{\text {a }}$ ed. Farmington Hills: Thomson Gale, 2005, p. 64956500. Portuguese translation by Fábio L. Stern \& Carlos Q. Bein Disponível:

https://www.academia.edu/25678254/Movimento_da_Nova_Era, acesso em 30/07/2020.

HARRIS, Sam. O Fim da Fé: religião, terrorismo e o futuro da razão. Lisboa: Tinta da China, 2007.

A Paisagem Moral: como a ciência pode determinar os valores humanos.

São Paulo: Companhia das Letras, 2013.

Despertar: um guia para a espiritualidade sem religião. São Paulo:

Companhia das Letras, 2015.

HERMANN, Jacqueline. História das religiões e religiosidades. CARDOSO, Ciro Flamarion \& VAINFAS, Ronaldo (org.) Domínios da História: ensaios de teoria e metodologia. Rio de Janeiro: Campus, 1997

HERVIEU-LÉGER, Danièle. O peregrino e o convertido: a religião em movimento. Petrópolis: Vozes, 2015

KLIM, Max. A História reinterpretada pela Astrologia. Rio de Janeiro, RecordNova Era:2000

MAGNANI, José. O neo-esoterismo na cidade. IN: Revista USP, São Paulo, 1996.

O circuito neo-esotérico na cidade de São Paulo. IN: A Nova Era no

Mercosul. Rio de Janeiro, Petrópolis, Vozes: 1999

MOREIRA, Leonardo. Ainda encantados? neoateísmo e desencantamento do mundo. Dissertação de Mestrado. São Paulo, PUC, 2014.

OLIVEIRA, Amurabi. NOVA ERA E NEW AGE POPULAR: as transformações nas religiões brasileiras. IN: Cad. De Pesq. Interdisc. Florianópolis, 2011.

REVISTARELEGENSTHRÉSKEIA - 2020 - UFPR 
PIERUCCI, Flávio. Secularização em Max Weber: da contemporânea serventia de voltarmos a acessar aquele velho sentido.IN: Revista Brasileira de Ciências Sociais. Vol. 13, n. 37, São Paulo, 1998.

TAYLOR, Charles. As fontes do Self: a construção da identidade moderna. Edições Loyola: São Paulo, 1997.

VOLCAN, Sandra; SOUSA, Paulo; MARI, Jair e HORTA, Bernardo. Relação entre bemestar espiritual e transtornos psiquiátricos menores: estudo transversal. IN: Revista Saúde Pública. 2003;37(4):440-5.

WEBER, Max. A ética protestante e o espírito do capitalismo. São Paulo: Companhia das Letras, 2013.

ZIZEK, Slavoj. Bem-vindo ao deserto do real. São Paulo: Boitempo editorial, 2003. 